The BDJ News section accepts items that include general news, latest research and diary events that interest our readers. Press releases or articles may be edited, and should include a colour photograph if possible. Please direct your correspondence to the News Editor, Arveen Bajaj at the BDJ, The Macmillan Building, 4 Crinan Street, London N19XW or by email to bdj@bda.org

\section{Calling candidates for BDA committees}

This autumn the British Dental Association (BDA) will be conducting elections for all of its governing committees. This includes the BDA's main committee, the Representative Body, and committees representing each area of the profession.

To represent members' interests properly, the $\mathrm{BDA}$ is keen to attract a wide range of candidates to reflect the diversity of the profession. Therefore it particularly welcomes and encourages candidates from currently under-represented groups, particularly women, young members, members of ethnic minorities, and dentists who qualified overseas.

More details are in the September issue of BDA News and at www.bda.org. If you would like any further information or would be interested in standing in any of these elections, you can request a nomination form by emailing gettinginvolved@bda.org or by telephoning 0207563 4579. The closing date for nominations is Monday 7 November. Elections to the General Dental Practice Committee work to a different timetable, and have been publicised widely within the dental press. The closing date for that election is 4 October.

\section{First for WHO Oral Health Bulletin}

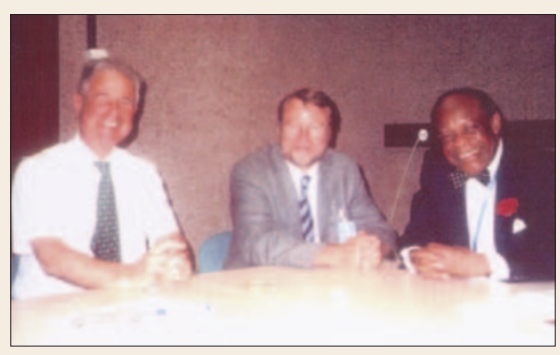

Dr I. G. Neil (Editor WHO Bulletin), Dr Poul Erik Petersen and Dr S. P. Akpabio, OBE, Founder President of the Commonwealth Dental Association discuss the special edition of the WHO Bulletin.

\section{Boosting dental registration for children}

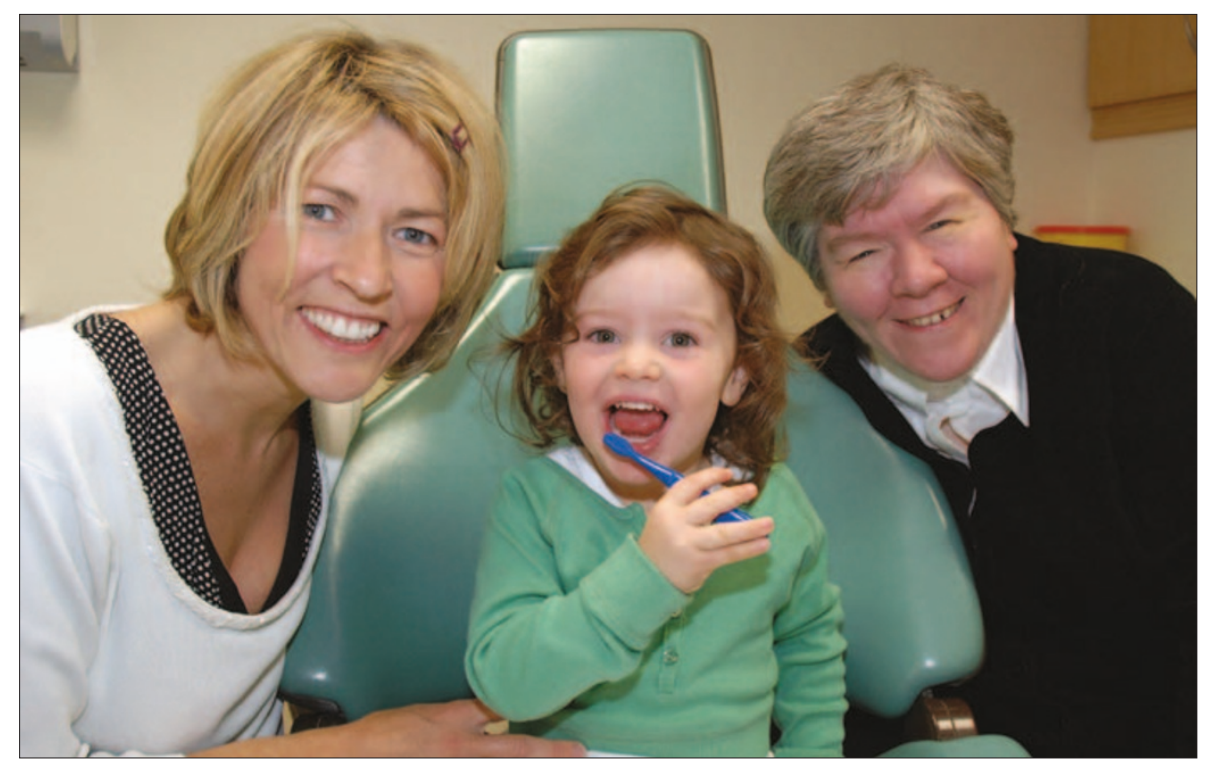

Two Dental Surgeries in Portglenone, Northern Ireland, have joined forces to increase dental registration in the 0-5 year-old-age group in the area. The initiative, which was developed in response to a lower than average registration of 0-2 year-olds in the Portglenone area last year, has already proved successful as figures indicate that the registration level has risen recently. Children who become registered with either of the dental practices will receive a free goodie bag funded by the Mid Ulster Local Health and Social Care Group (LHSCG). The bag contains a baby toothbrush, baby toothpaste, an adult toothbrush and toothpaste and a guide to dental health for both children and families. Laurence O'Kane, Chair of the Mid Ulster LHSCG, emphasised the role of parents and guardians in their child's dental health. "Northern Ireland has the highest rates of dental decay levels in the UK for children of all ages. Parents have a key role in determining their children's current and future oral health as their oral health and attendance levels strongly influence those of their children. Parents and guardians also control the factors that affect the child's chance of developing dental decay, including their diet, tooth brushing behavior and dental attendance patterns." Pictured above, two-year-old Ciara Kelly from Gulladuff, demonstrates her tooth brushing skills to Dr Anne O' Rawe from Portglenone Dental Surgery and Avril Craig, Locality Partnership Officer from Mid Ulster LHSCG.
The latest WHO Bulletin has dedicated an entire issue to oral health for the first time. This special edition of the journal was launched on 9 September at the World Congress on Preventive Dentistry in St George's Hall, Liverpool by Dr Poul Erik Petersen, group leader of WHO's Global Oral Health Programme.

The issue covers themes such as WHO's action for continuous improvement in oral health, tobacco or oral health, oral health, general health and quality of life, oral health for ageing populations, dental care in Burkino Faso, fluorides: a public health success, principles of oral health promotion and several other items. All the articles in this issue are viewable free of charge by visiting the WHO Bulletin website at www.who.int/bulletin/en.

\section{Death notice}

Keith Woods died on 17 September 2005, aged 64. Before his retirement in 2001 he was NHS Consultant in Dental Public Health for North West Lancashire Health Authority and Morecambe Bay Health Authority. He also held the post of Director of the North West Region Dental Public Health Resource Centre.

An obituary will be included in a future issue of the $B D J$. 


\section{England's Chief Dental Officer stands down}

Professor Raman Bedi stood down as Chief Dental Officer for England at the beginning of this month, after three years in the post. He leaves to take up his chair at King's College London and take forward the establishment of a global Child Dental Health Taskforce.

During his time at the Department of Health, Professor Bedi has overseen reforms in dentistry including the Health and Social Care Bill (2003), Fluoridation clauses in the Water Act (2003) and a section 60 order to reform and strengthen the General Dental Council (2005). In addition there has been an expansion of the dental workforce, a 25 per cent increase in undergraduate dental student numbers, the move to local commissioning of NHS dental services and new contractual arrangements for dentists, backed by proposals for a fundamental change in charging patients for NHS care and treatment.

Professor Raman Bedi said, "It has been an exciting and challenging time for dentistry and I am grateful for so many in the dental profession who have helped in shaping and taking forward our dental reforms. I believe these will transform the oral health of England and make our services the envy of the world."

The Department of Health has asked Barry Cockcroft and Tony Jenner to take up the respective posts of $\mathrm{CDO}$ and Deputy CDO on an acting basis. The BDA said that it expected a high-level and timely replacement for Professor Bedi and that this crucial post should retain the current CDO's rank within the Department of Health.

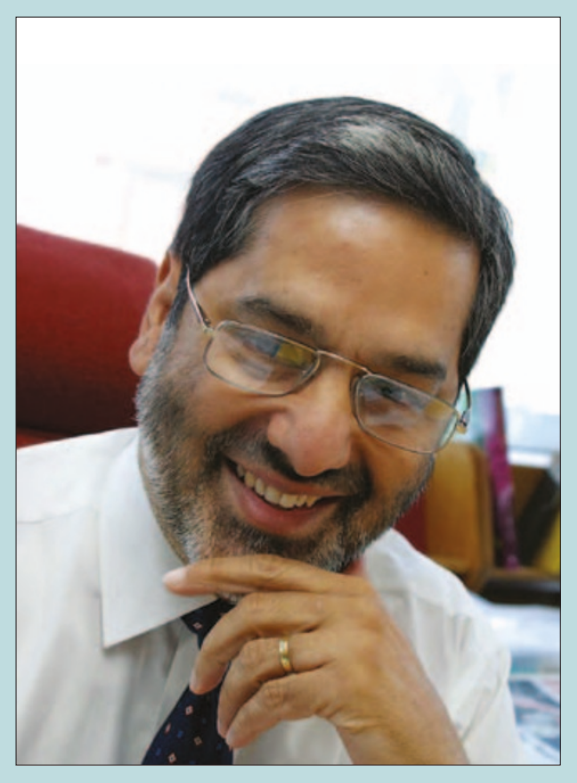

\section{New organisation launched}

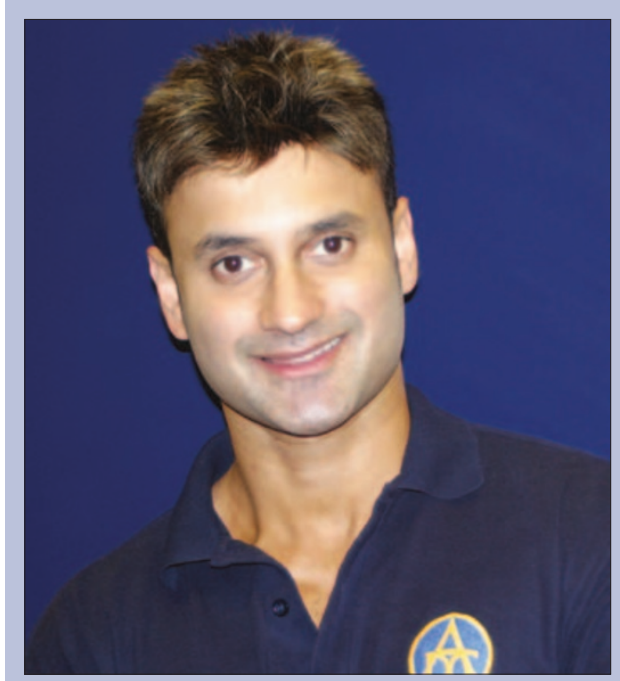

IAAFA president Dr Bob Khanna
The International Academy of Advanced Facial Aesthetics (IAAFA) was launched last month in response to an increase in the uptake of procedures in facial aesthetics in the UK in recent years.

The organisation aims to unite all dental and medical professionals providing treatments within the realms of facial aesthetics from cosmetic dental surgeons and oral maxillofacial surgeons to ENT and plastic surgeons.

The IAAFA's elected president Dr Bob Khanna believes it is vital that dental surgeons are appropriately represented and duly respected for their unique skills in performing not only advanced reconstructive and aesthetic dentistry but non-surgical facial procedures e.g. botulinum toxin (BTX) and dermal fillers and emphasised the importance of maintaining consistent and productive dialogue with the HealthCare Commission in light of imminent regulatory guidelines.

Dr Khanna commented, "It is clear that in this climate of increased awareness and demand for treatments by patients that a truly symbiotic and multi-disciplinary approach is required as a pre-requisite to optimising treatment results. Working alongside the Heath Care Commission, the IAAFA aims to provide support and guidance protocols for all professionals concerned, as well as being a vehicle for the best interdisciplinary teaching in the world for all aspects of cosmetic dentistry and facial aesthetic medicine." For further details visit www.iaafa.net. 


\section{Decontamination methods not up to scratch says study}

Endodontic files are not reliably decontaminated using procedures readily available in general dental practice, according to a study to be published in the next issue of the $B D J$. The study examined methods used for reprocessing endodontic instruments in general dental practice and determined the degree of residual visual contamination and blood contamination on 250 reprocessed files collected from 25 general dental practices. It found that $75 \%$ of files showed visible evidence of contamination and 7\% of files had residual blood deposits.

In A study of visual and blood contamination on reprocessed endodontic files from general dental practice by S Letters, AJ Smith, S McHugh and J Bagg, questionnaires were sent to 25 general dental practitioners to obtain information on the re-processing of used endodontic files.

Ten files which had been used, reprocessed and were ready for use were also collected from each practice and were examined under a dissecting light microscope for residual contamination and then tested for blood deposit.

The study discovered that blood contaminated files were significantly more heavily contaminated when examined visually and that large variations were found in residual contamination of files collected from practices using the same methods of decontamination. In their discussion the authors highlighted that while all practitioners re-used endodontic files, the variations in decontamination methods reported indicate a lack of clarity on best practice and that the study demonstrates that endodontic files are not reliably decontaminated by methods currently employed in dental practice.

Dr Andrew Smith, senior lecturer in Oral Microbiology at the University of Glasgow Dental School commented, "Endodontic files are another example of medical devices that are very difficult to clean and effective cleaning of a re-usable device is essential to ensure the efficacy of the sterilisation process. Clean instruments are also essential to reduce the risk of iatrogenic CJD. This study has shown that under general practice conditions these devices cannot be reliably cleaned and must be viewed as single use devices. In turn practitioners must be adequately recompensed for endodontic files in their switch to single use."

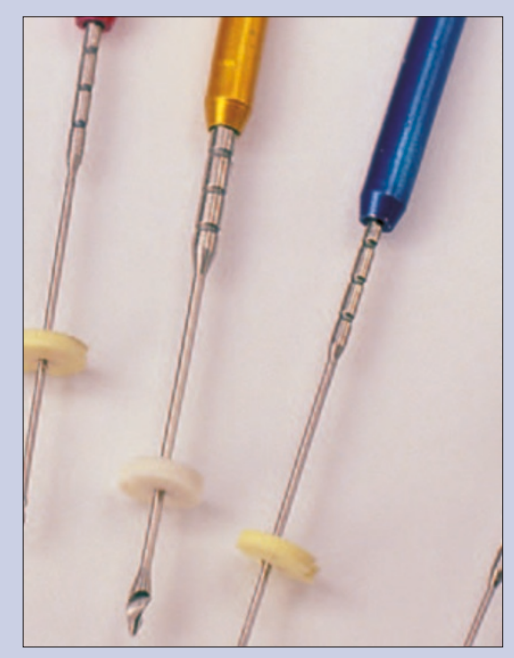

\section{Name change for PCDs}

Professionals complementary to dentistry (PCDs) will now be collectively known as dental care professionals (DCPs). The name change was agreed by the General Dental Council (GDC) at its September meeting, and applies to dental hygienists, dental therapists, and the four groups of professionals who will start registering with the GDC for the first time in July 2006. These are dental nurses, dental technicians, clinical dental technicians and orthodontic therapists. The change has been made in order to be consistent with terminology used in the Dentists Act which was recently amended to give the GDC a range of new powers, including the power to start registering other dental team members.

\begin{tabular}{|l|l} 
Hew Mathewson, President of the General \\
Dental Council said, "The term 'dental care pro- \\
fessional' sums up the important role these \\
members of the dental team play in patient care. \\
The name change does not affect the respective \\
titles of the individual professions - a dental \\
hygienist will still be known as a dental hygien- \\
ist, and a dental nurse will still be a dental \\
nurse." For more information about DCP regis- \\
tration visit www.gdc-uk.org.
\end{tabular}

\section{DIARY}

October 2005

British Dental Trade Association International Dental Showcase 2005

Date: 06-08.10.05

Venue: NEC Birmingham

Tel: 08702413365

www.dentalshowcase.com

Dentaid CPD Day

Date: 15.10 .05

Venue: King's College, London

Tel: 01794324249

www.dentaid.org

33rd International Expodental

Date: 19-21.10.05

Venue: Pavilions 20 \&t 21 Fiera Milano

City, Milan, Italy

www.expodental.it

BDA North of Scotland Branch Young Dentists Conference and Ceildh

Date: 22.10.05

Venue: Dundee Dental Hospital and

School, and the Apex Hotel and Spa,

Dundee

Contact: Frankie Soldani

Tel: 01382635962

DenTech China 2005

Date: 26-29.10.05

Venue: Shanghai Everbright Convention \& Exhibition Center, Shanghai

Tel: 86-21-6294 6966

Fax: 86-21-6280 0908

Email:mail@showstar.net

www.dentech.com.cn

\section{November 2005}

British Association of Cosmetic Dentistry 2005 Conference

Date: 18-19.11.05

Venue: Victoria Plaza Hotel, London

Tel: 02076124166

Fax: 02071827123

Email: info@bacd.com

www.bacd.com

2nd European Congress on the

Reconstruction of the Periodontally Diseased Patient

Date: 25-27.11.05

Venue: Radisson SAS Scandinavia Hotel, Copenhagen

Email: kongress@quintessenz.de

www.quintessenz.de/ecrp

Greater New York Dental Meeting

Date: 25-30.11.05

Venue: New York

Email: info@gnydm.com

www.gnydm.com 


\section{Neanderthal teeth shed new light}

Neanderthals may not have been as different from modern humans as some researchers have thought, new findings suggest. The study, Anterior tooth growth periods in Neanderthals were comparable to those of modern humans by researchers from Ohio State University, USA and the University of Newcastle in the UK, has found that the rate of tooth growth present in the Neanderthal fossils they examined was comparable to that of three different populations of modern humans. This challenges research that suggests that ancient Neanderthals might have had an accelerated childhood compared to that of modern humans.

"Based on our study of the enamel of these Neanderthal teeth and other modern ones, we can't support the claim that Neanderthals grew up more quickly than modern humans do," said one of the authors of the study Debbie Guatelli-Steinberg, Assistant Professor of Anthropology at Ohio State University.

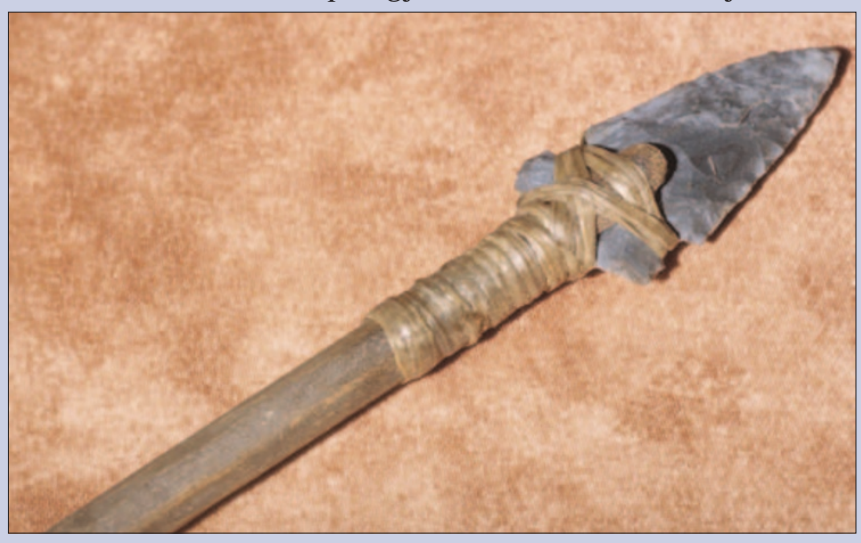

By examining enamel formation in anterior teeth, the team compared the dental growth rate of Neanderthals to those of three modern populations - people currently living in Newcastle-upon-Tyne, indigenous people from South Africa, and Inuit from Alaska dating from 500 B.C. until the present.

"We chose these three groups since they would provide a good cross-section of various populations from different regions of the world," she said. "We feel that they give us some insights into the variation that exists within modern humans."

The researchers used precise dental impressions made of 55 teeth believed to come from 30 Neanderthal individuals. These were compared to 65 teeth from 17 Inuit, 134 teeth from 114 South Africans and 115 teeth from as many Newcastle residents. Professor Guatelli-Steinberg said that the results showed that the enamel formation times for the Neanderthals fell easily within the range of time shown by teeth from the three modern populations - a conclusion that did not support a shorter childhood for the Neanderthals.

However, the new findings haven't convinced the researchers that a Neanderthal childhood was equal to a modern human's. "The missing key bit of data to show that would be evidence for when the first molar tooth erupted in the Neanderthals, and we simply have no evidence of when that occurred," Professor Guatelli-Steinberg said.

The study appeared in last month's issue of the Proceedings of the National Academy of Sciences. Donald J Reid, lecturer in Oral Biology at the University of Newcastle, Thomas A. Bishop, associate professor of statistics, and Clark Larsen, Professor and chair of Anthropology, both at Ohio State, were co-authors in the study.

\section{New technique can help identify disaster victims}

A new tooth enamel dating technique is providing forensic scientists with a more precise way to determine a person's age at the time of death. The method, which looks at the radioactive carbon-14 produced by above-ground nuclear testing in the 1950s and 1960s could be used to help in the identification of victims of Hurricane Katrina and other large-scale disasters. The technique was developed by researchers at Lawrence Livermore National Laboratory (LLNL) and the Karolinska Institute in Sweden, and determines the amount of carbon-14 in tooth enamel. Scientists can relate the extensive atmospheric record for carbon-14 to when the tooth was formed and calculate the age of the tooth, and its owner, to an accuracy of within about 1.6 years.

Bruce Buchholz of LLNL's Center for Accelerator Mass Spectrometry, where the enamel samples were analysed said, "Whatever carbon gets laid down in enamel during tooth formation stays there, so tooth enamel is a very good chronometer of the time of formation. If you look at multiple teeth formed at different times, you can get (the age range) even tighter." Previous techniques, such as evaluating skeletal remains and tooth wear, are accurate only to within five to 10 years in adults, Buchholz said.

He added that Swedish forensic scientists had already used enamel dating to help narrow the search for victims of last December's tsunami in Southeast Asia. Livermore officials are providing information on the enamel dating technique to federal agencies as part of the Laboratory's scientific and technical assistance in response to Hurricane Katrina. This same technology was deployed in the days following the September 11 attacks in New York's World Trade Center rubble.

Carbon-14, or radiocarbon, is naturally produced by cosmic ray interactions with air and is present at low levels in the atmosphere and food. Atmospheric testing of nuclear weapons from 1955 to 1963 produced a dramatic surge in the amount of radiocarbon in the atmosphere. Buchholz explains, "Even though the detonations were conducted at only a few locations, the elevated carbon-14 levels in the atmosphere rapidly equalised around the globe."

Since atmospheric testing was banned in 1963, the levels have dropped substantially as the carbon-14 reacted with oxygen to form carbon dioxide, which was taken up by plants during photosynthesis and mixed with the oceans.

"Because we eat plants and animals that live off plants, the carbon-14 concentration in our bodies closely parallels that in the atmosphere at any one time," he said.

Buchholz and his colleagues analysed 33 teeth from 22 different people whose ages were known. The research was reported in September issue of the journal Nature.

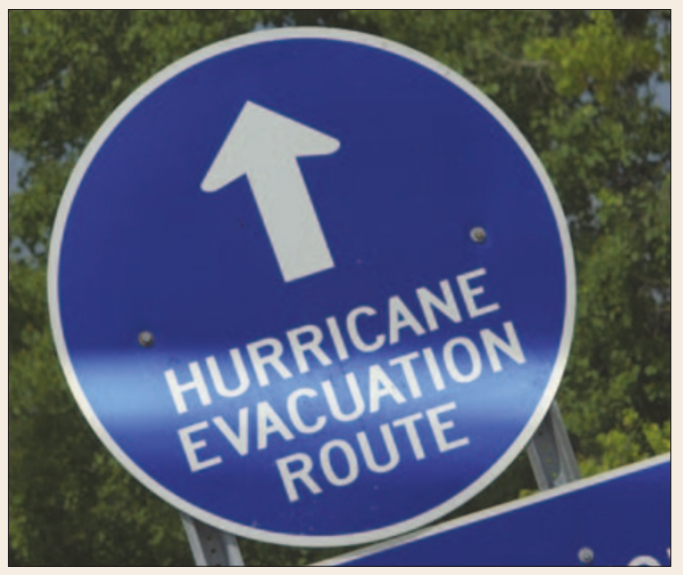




\section{Periodontal disease affects young adults}

Periodontal disease develops much earlier than dentists and other health professionals thought, a new study concludes. Clinicians found a significant proportion of young adult patients examined had well-established periodontal disease despite no signs or symptoms, while affected pregnant women faced more than twice the risk of preterm birth and other pregnancy complications as unaffected women, the research also revealed.

The study from the universities of North Carolina and Kentucky, USA, took an in-depth look over time at the condition in wisdom teeth in young adults.

"About seven years ago, we were asked to spearhead a series of clinical trials to look at what happens if you keep your wisdom teeth and what happens if you have them taken out," said study leader Dr Raymond P. White Jr, Professor of oral and maxillofacial surgery at the UNC School of Dentistry.

"Part of the reason was that research at UNC and elsewhere showed that the inflammation in the mouth caused by periodontal infections promoted inflammation in other parts of the body, which contributed in significant ways to coronary artery disease, stroke, kidney disease and obstetric complications," White said. "Another reason was that there has been an increased emphasis on evidence-based medicine over the past decade or so."

The team collected baseline data on about 400 people who planned to keep their wisdom teeth. It surprised the team that a quarter of patients in their 20 s had periodontal problems with no symptoms, as it is assumed that the disease affects the older age group of over $35 \mathrm{~s}$.

In the evaluation of data from 1,020 higher-risk obstetrics patients enrolled in a National Institutes of Health-sponsored clinical trial, 18 percent delivered preterm, he said. Wisdom teeth were a major contributor to the young women's periodontal disease, and the severity of their disease clearly corresponded with the risk of preterm delivery. It also corresponded with indicators of systemic inflammation, such as elevated C-reactive protein, a substance produced by the liver in response to inflammation anywhere in the body.

Women with the worst periodontal disease around their third molars had more than twice the risk of preterm birth, researchers found. White said that since untreated periodontal disease in effect "seeds" the bloodstream with diseasecausing bacteria, it's important that dentists, obstetricians and other physicians assess wisdom teeth when examining young adults.

"Although most people eventually will develop pathology with wisdom teeth, periodontal disease, pericoronitis or tooth decay, it is too early to recommend strongly that everyone has their wisdom teeth removed," he said. "It is a good idea to have third molars evaluated before age 25 , but since a quarter of people will never have problems with them, a lot depends on how risk-averse one is as to whether their third molars with no detected pathology should be extracted as a precaution."

\section{Training set to improve dentistry in rural areas}

A new training initiative has been launched in Scotland that will improve care levels to rural areas. The new initiative from NES Scotland and the Scottish Executive will train dentists to an MSc in Clinical Dentistry, enabling them to provide intermediate and higher care levels in rural areas of Scotland while providing dental surgeons working in the rural areas with access to postgraduate training at the Scottish University Dental Schools.

The Scottish Dental Postgraduate Training Fellowship will assist the Scottish Health Boards in attracting dental surgeons to the rural areas, and in providing a level of specialist dental care which will be accessible to rural patients.

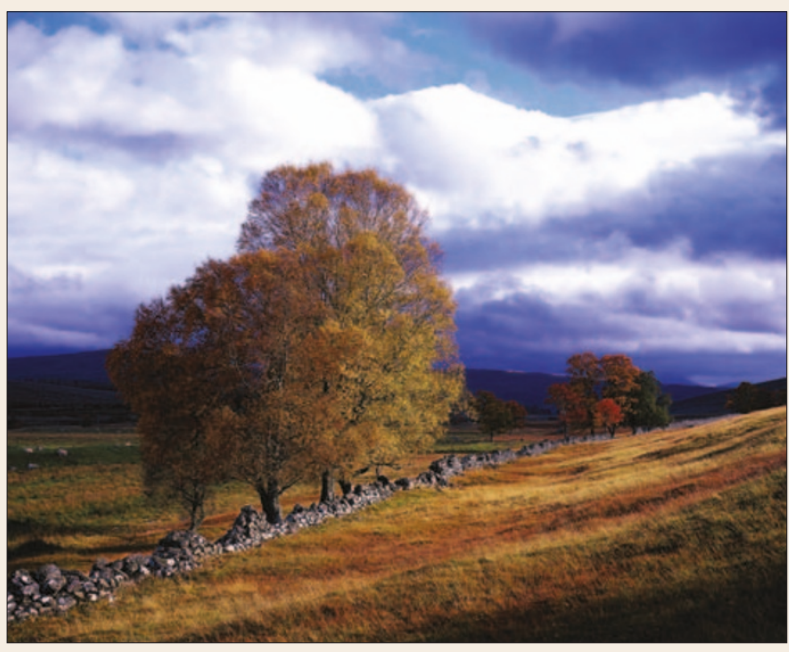

Funding has been established for three postgraduate places per year, and the MSc courses will be arranged over three years. Fellows will attend one of the Scottish Dental Schools on a part-time basis (either one week per month or two days per fortnight) to complete a clinical research project and formal teaching programme. Successful candidates will be offered a position as a salaried practitioner with one of the rural Health Boards, and a service rotation will be in place.

Entrance to MSc courses is available to dental graduates who have completed MFDS, but mentoring will be given to those who, having completed Vocational Training or General Professional Training, wish to sit the MFDS examination during the first year of the Fellowship.

The University training programme will commence in each academic year, however candidates who wish to join during an academic year will be included in an initial clinical training programme and will enter the MSc programme in the following year. 